\title{
Investigation on Vehicle Dynamic Behaviour During Emergency Braking at Different Speed
}

\author{
I. M. Zulhilmi ${ }^{1}$, P. M. Heerwan ${ }^{1,2^{*}}$, R. I. M. Eiman, I. M. Izhar and S. M. Asyraf ${ }^{1}$ \\ ${ }^{1}$ Faculty of Mechanical and Manufacturing Engineering, Universiti Malaysia Pahang, \\ 26600 Pekan, Pahang, Malaysia \\ *Email: mheerwan@ump.edu.my \\ Phone: +6094246284; Fax: +6094246222 \\ ${ }^{2}$ Automotive Engineering Centre, Universiti Malaysia Pahang, \\ 26600 Pekan, Pahang, Malaysia
}

\begin{abstract}
Safety system of the vehicle can be divided into two main categories; passive and active safety system. The purpose of the passive safety system is to protect the occupant during an accident, while active safety system allows the vehicle to be manoeuvred to avoid any collision. Although active safety system can prevent the accident, in a critical situation such as emergency braking, the dynamic behaviour of the vehicle changes abruptly, and the vehicle becomes unstable. The objective of this study is to analyse the dynamic behaviour of the vehicle during emergency braking with and without anti-lock braking system (ABS). In this study, the dynamic behaviour of the vehicle is observed by the simulation model that has been developed in the MATLAB-Simulink. The analysis vehicle model is Universiti Malaysia Pahang (UMP) test car, model Proton Persona. During braking, when ABS control unit detect the wheel is to lock-up, the hydraulic control unit closed the hydraulic valve to release the brake pad on the wheel. This allows the wheel to spin intermittently during braking. From the simulation results, when ABS is not applied to the vehicle, the front tires were lock-up and the vehicle become skidding. However, when ABS is applied, the speed of all tires decreased gradually and the vehicle is not skidding. The simulation results also show that the stopping distance with ABS is improved $28 \%$ compared without ABS.
\end{abstract}

Keywords: active safety system; anti-lock braking system (ABS); hydraulic braking system, vehicle dynamic; skid.

\section{INTRODUCTION}

In Malaysia, vehicle accident is responsible for the death of around 7,000 road user annually and thousands of other injuries [1]. Among ASEAN countries, in 2007, Malaysia has recorded the highest rate of road accident per 100,000 populations [2]. Several factors contribute to the road accident such as inexperience, lack of skill, risk-taking behaviour, road conditions and bad weather [3, 4]. To increase the safety of the vehicle, most of the researchers are focusing on the active and passive safety system, such as yaw moment control, stability control, braking and steering control [5-10]. Active safety system can prevent the vehicle from a collision, while passive safety system keeps the driver and passengers safe if the accident occurs $[6,11]$.

Braking system is a basic active safety system and it is compulsory for any vehicles. By applying the force to the brake pedal, the speed of the vehicle can be reduced and finally stop it from moving. In this process, the kinetic energy from the wheel is converted to the thermal energy at the brake pads and the road-tire interface [12]. Although braking system can 
prevent the vehicle from collision, it also has some limitation such as during braking on the slippery surface. In this condition, if an active safety system such as an anti-lock brake system (ABS) is not applied, the tire stopped rotating rapidly and the vehicle skidded [13, 14].

The skidding phenomenon also can be occurred during panic and emergency braking. When the driver pushes a brake pedal firmly, the speed of the tire decreases rapidly and due to the inertia, and the vehicle is skidding. An Autonomous Emergency Braking System (AEB) is introduced to overcome with this issue. If an unexpected obstacle approaches the vehicle, the AEB system automatically activated the brake actuator to stop the vehicle [15-17]. In addition, the AEB system also can help to provide the optimum braking force if a force from the driver is not enough to stop the vehicle in the safety range. Studies show that male and female drivers have different capabilities to exert a maximum pedal force [13]. Then, the AEB system seems to be very practical for this situation.

The objective of this study is to analyse the vehicle dynamic behaviour during emergency braking at different speed. Due to the safety factor, the analysis is developed in the MATLAB-Simulink software. The results from the simulation is reliable because the analysis vehicle model is based on the actual car, which is Vehicle Global Positioning System (VGPS), Universiti Malaysia Pahang (UMP) Test Car. All the specifications and parameter in the numerical analysis is same as the actual value from the VGPS UMP Test Car. In the numerical analysis, the maximum braking force is set constant to $400 \mathrm{~N}$ and the initial speed of the vehicle is set to the three different speeds; $30 \mathrm{~km} / \mathrm{h}, 50 \mathrm{~km} / \mathrm{h}$ and $70 \mathrm{~km} / \mathrm{h}$. The initial speed is set into three categories to analyse either the speed can affect the braking performance of the vehicle.

\section{ANALYSIS VEHICLE MODEL}

Figure 1 shows the VGPS UMP Test Car that has been used as the analysis vehicle model in the numerical analysis. This vehicle is equipped with the advanced sensors to analyse the dynamics motion of the vehicle. The specifications of this vehicle are shown in Table 1.

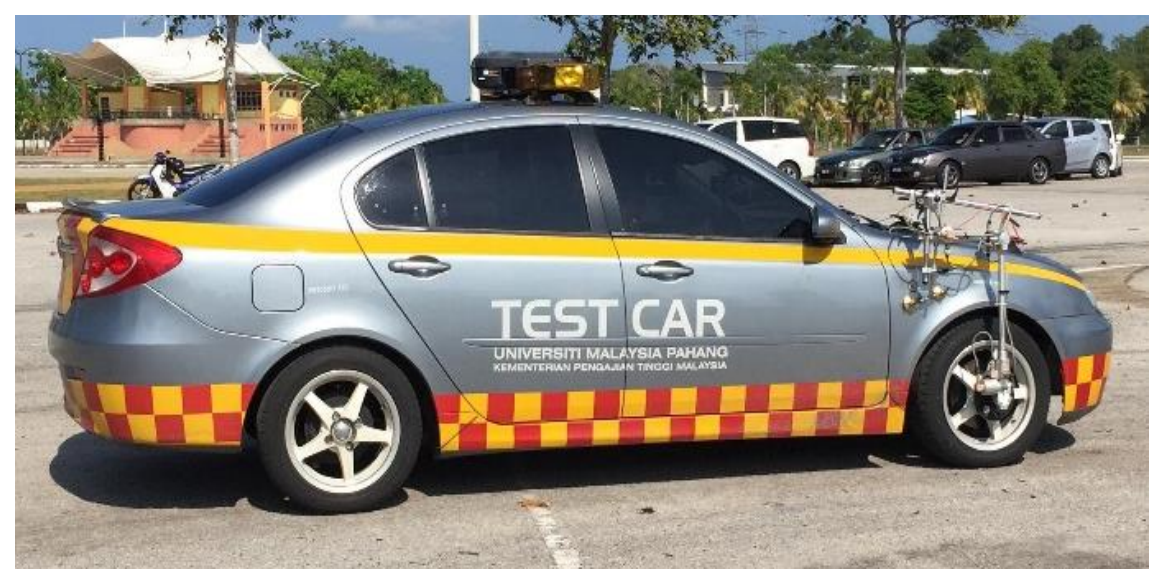

Figure 1 Vehicle model, UMP Test Car.

\section{Brake System of the Vehicle Model}

The braking system of the VGPS UMP Test Car is the hydraulic braking system, with disc brake at the front tire and drum brake at the rear tire. Generally, most of the sedan vehicles have drum brakes at the rear tire to reduce the maintenance cost. Although the braking performance of disc brake is faster than the drum brake, the brake pads, calliper and disc rotor need to be serviced timely. In contrary with the drum brake, the material of the brake shoes is durable and long lasting. Besides that, the drum brake also suitable for the parking brake. 
Table 2 shows the parameters of the braking system for VGPS UMP Test Car. This braking system is a closed-loop braking system which means that the pressure from the master cylinder is transmitted equally to all parts. Based on the Pascal's Law, the pressure at the wheel cylinder and brake calliper can be adjusted by increasing or reducing the diameter of the piston.

Table 1. Specifications of the vehicle.

\begin{tabular}{lc}
\hline Parameter & Value \\
\hline Gross weight of vehicle, $\mathrm{W}(\mathrm{kg})$ & 1330 \\
Length of vehicle, $\mathrm{L}(\mathrm{m})$ & 4.477 \\
Vehicle width, $\mathrm{D}(\mathrm{m})$ & 1.725 \\
Wheel base, $l(\mathrm{~m})$ & 2.6 \\
Front track of vehicle, $\mathrm{d}_{\mathrm{f}}(\mathrm{m})$ & 1.475 \\
Rear track of vehicle, $\mathrm{d}_{\mathrm{r}}(\mathrm{m})$ & 1.470 \\
Height of CG, $\mathrm{h}(\mathrm{m})$ & 0.479 \\
Ground coefficient of friction, $\mu$ & 0.9 \\
Vehicle drag coefficient, C & 0.32 \\
Wheel radius, $\mathrm{r}_{\text {wheel }}(\mathrm{m})$ & 0.297 \\
\hline
\end{tabular}

Table 2. Parameters of the brake.

\begin{tabular}{lc}
\hline Parameter & Value \\
\hline Pedal ratio & 7.1 \\
Master cylinder piston area, $\mathrm{A}_{\mathrm{m}}\left(\mathrm{m}^{2}\right)$ & 0.000387 \\
Wheel cylinder piston diameter, $\mathrm{d}_{\text {cylinder }}\left(\mathrm{m}^{2}\right)$ & 0.01905 \\
Drum effective radius, $\mathrm{r}_{\text {drum }}(\mathrm{m})$ & 0.1397 \\
Brake calliper diameter, $\mathrm{d}_{\text {calliper }}(\mathrm{m})$ & 0.054 \\
Brake pad effective radius, $\mathrm{r}_{\text {brake }}(\mathrm{m})$ & 0.102 \\
Drum brake lining brake factor & 2.2 \\
Disc and pad brake factor & 1.2 \\
Friction coefficient of contact surface & 0.4 \\
\hline
\end{tabular}

When a driver pushes a brake pedal, the pedal force, $F_{p}$ is exerted on the brake pedal. The pedal ratio is the quantitative relation between the distance of pedal to pivot and pushrod. Figure 2 shows the mechanism of the brake pedal.

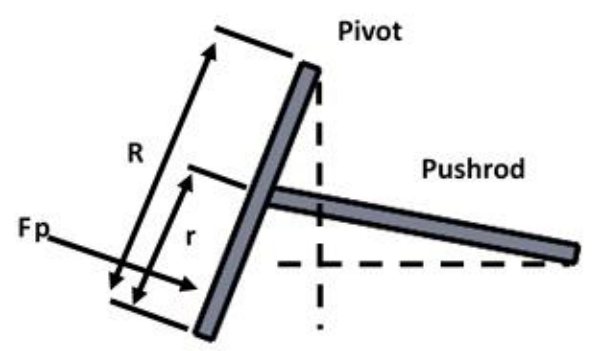

Figure 2. Brake pedal mechanism.

Multiplying both the pedal force and the pedal ratio gives the force at master cylinder, $F_{m}$ as in Eq. (1). 


$$
F_{m}=F_{p} \times\left(\frac{R}{r}\right)
$$

Then, the pressure inside the master cylinder, $P_{\text {hyd }}$ can be determined by dividing the force at master cylinder, $F_{m c y l}$ with the area of master cylinder, $A_{m c y l}[18]$.

$$
P_{h y d}=\frac{F_{m c y l}}{A_{m c y l}}
$$

Considered that the pressure is equal throughout the system, by multiplying the hydraulic pressure with piston area at the brake piston, $A_{b r}$ piston produces actuating force on the brake, $F_{a}$.

$$
F_{a}=P_{\text {hyd }} \times A_{b r \text { piston }}
$$

Figure 3(a) shows the forces acting on the drum brake while Fig 3 (b) shows the forces acting on disc brake. The actuating forces produces braking torque at the wheel which caused the wheel to slow down and eventually stop. Multiplication of the actuating force and the effective radius gives braking torque.

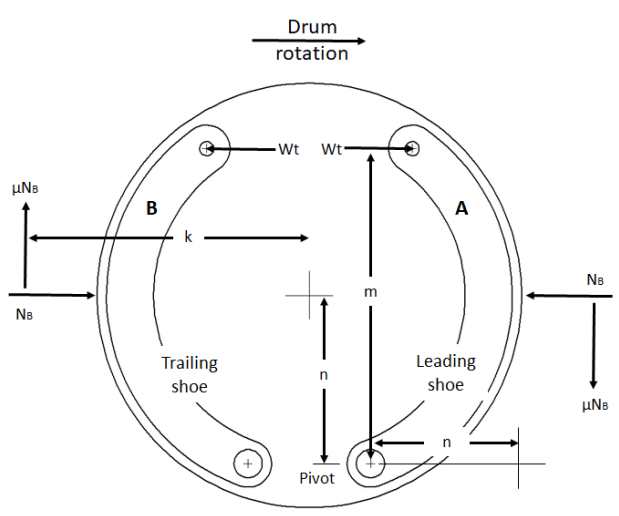

(a)

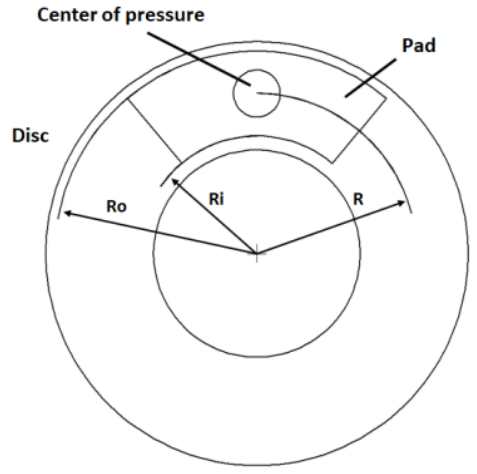

(b)

Figure 3. Forces acting on (a) drum brakes and (b) disc brakes.

For drum brakes, moment of all forces about the pivot give,

$$
\begin{aligned}
& T_{l}=\mu N_{A} k=\frac{W_{l} m \mu k}{n \sin \theta-\mu(k-n \cos \theta)} \\
& T_{t}=\mu N_{B} k=\frac{W_{t} m \mu k}{n \sin \theta+\mu(k-n \cos \theta)}
\end{aligned}
$$

Taking that $W_{l}=W_{t}=F_{a}$ and $\theta=90^{\circ}$, hence; 


$$
T_{l}=\frac{F_{a} m \mu k}{n-\mu k} \quad \text { and } \quad T_{t}=\frac{F_{a} m \mu k}{n+\mu k}
$$

The summation of both leading and the trailing braking torque yields the total braking torque at the drum brakes.

$$
T=T_{l}+T_{t}
$$

For disc brakes, the actuating force pushes the piston against the rotor creating retarding torque on the disc brake.

$$
\begin{aligned}
& F_{\text {clamp }}=2 F_{a} \\
& F_{\text {friction }}=\mu F_{\text {clamp }} \\
& T_{b r}=F_{\text {friction }} r_{\text {eff }}
\end{aligned}
$$

The braking torque on disc brakes can be written as Eq. (11).

$$
T_{b r}=2 \mu F_{a} r_{e f f}
$$

By multiplication of traction force and radius of the tire, the traction torque can be determined as Eq. (12).

$$
T_{f}=F_{x} r_{\text {tire }}
$$

Then, the distance travelled by the vehicle during braking is calculated by integrating the velocity of the vehicle given as in Eq. (13).

$$
X=X_{o}+V \int_{0}^{t} \cos (\beta+\theta) d t
$$

Considering that there is no lateral force involved, the net speed equals to the longitudinal speed. Since there is no steering angle, value of side slip angle, $\beta$ and tire steer angle, $\theta$ is zero. Therefore, $X_{o}$ is the initial value of distance. In this case, it is the initial braking point, hence, it is equal to zero. From there, the distance can be acquired by integrating the longitudinal speed of the car.

\section{NUMERICAL ANALYSIS}

Simulation conducted with three different initial speed and each of it with activation of ABS and without the activation of ABS. Three initial speed before panic braking applied are choose as $30 \mathrm{~km} / \mathrm{h}, 50 \mathrm{~km} / \mathrm{h}$ and $70 \mathrm{~km} / \mathrm{h}$. These three initial speeds are chosen based on the speed limit at the urban areas, unpaved road and rural paved road [13, 19]. 


\section{Dynamic Equation of Motion}

In the numerical analysis, the vehicle is considered braking in a straight line and only the longitudinal forces are considered.

$$
u=\int \frac{\sum F_{x}}{m}
$$

The longitudinal speed of the vehicle, $u$, is given by integration of the vehicle's longitudinal acceleration, $a$. Equation (15) and Eq. (16) show the vertical force at the front and rear tires. From these equations, it can be shown that the weight transfer is from the rear wheel to the front wheel. These equations also show that the longitudinal acceleration, $a$ of the car can affect the load at each tire. In an emergency braking, the value of $a$ increases rapidly and more weight transferred to the front wheel and the vehicle becomes unstable.

$$
\begin{aligned}
& F_{z F} n e w=F_{z F}+\Delta F_{z}=F_{z F}+\left(\frac{h}{l} \times m \times a\right) \\
& F_{z R} n e w=F_{z R}-\Delta F_{z}=F_{z R}-\left(\frac{h}{l} \times m \times a\right)
\end{aligned}
$$

The tractive force is the longitudinal force acting on the tire contact surface. Since there is no steering angle, only linear state is considered due to constant negative value of $\zeta$.

$$
\begin{aligned}
& F_{x}=\mu F_{z} \cos \theta \\
& \cos \theta=\frac{s}{\lambda} \\
& \lambda=\sqrt{s^{2}+\left(\frac{K_{b}}{K_{s}} \tan \beta\right)^{2}}
\end{aligned}
$$

The value for $F_{x}$ can be acquired from the multiplication of tire's vertical force with coefficient of friction between road and tire interface. The value of $\cos \theta$ is given by division of tire slip, $s$ with Lambda, $\lambda$. Taking that $\beta$ is $0, \lambda$ equals to the tire slip. Hence, giving out the value of $\cos \theta$ as 1 .

$$
\mu=\left[C_{1}\left(1-e^{-C_{2} s}\right)-C_{3} s\right] e^{-C_{4} s u}
$$

The tire-road adhesive friction is calculated using Burckhardt formulae. Equation 14 gives the value of tire adhesive friction. The parameters $C_{1}, C_{2}, C_{3}$ and $C_{4}$ are constants given from the following table. 
Table 3. Tire-road friction parameters [13].

\begin{tabular}{lcccc}
\hline Surface condition & $C_{1}$ & $C_{2}$ & $C_{3}$ & $C_{4}$ \\
\hline Asphalt, dry & 1.029 & 17.16 & 0.523 & 0.03 \\
Asphalt, wet & 0.857 & 33.822 & 0.347 & 0.03 \\
Cobblestones, dry & 1.3713 & 6.4565 & 0.6691 & 0.03 \\
Snow & 0.1946 & 94.129 & 0.0646 & 0.03 \\
Ice & 0.05 & 306.39 & 0 & 0.03 \\
\hline
\end{tabular}

$$
\begin{aligned}
& \text { slipratio, } s=\frac{u-r \omega}{u} \times 100 \% \\
& S D=\frac{v_{i}^{2}}{2 a_{x}} \\
& t_{s}=\frac{v_{i}}{a_{x}}
\end{aligned}
$$

The slip ratio value is used for the ABS mechanism. The braking torque is set to zero if the slip value is greater than 0.3 . The stopping distance and stopping time can be calculated from Eq. (16) and Eq. (17) where, $v_{i}$ is the initial speed during braking and $a_{x}$ is the vehicle deceleration during braking. Braking torque is subtracted from the traction torque as it opposes each other. The product of the subtraction is divided by the tire's inertia which give out the angular acceleration of the tire. By integrating the angular acceleration yields the angular velocity of the tire. Then, the tire speed can be acquired by multiplying together the angular velocity and the tire's radius.

$$
\begin{aligned}
& \frac{T_{f}-T_{b r}}{I_{\text {tire }}}=\frac{d \omega}{d t} \\
& \int \frac{d \omega}{d t}=\omega \\
& v_{\text {tire }}=r_{\text {tire }} \omega
\end{aligned}
$$

\section{Anti-lock Brake System (ABS)}

ABS is used to initiate the pumping action, brake and release in split of seconds for a period of time, when triggered to avoid wheel lockup during braking which caused skidding. In this study, a simulation model of brake system with ABS has been developed in MATLAB-Simulink. In numerical analysis, based on Figure 4, the optimum value of slip ratio, $s$ for a dry road can be considered in between of 0.08 to 0.3 [13]. As the vehicle slip ratio is in range of $s_{u p}=0.08$ and $s_{\text {down }}=0.3$, it can obtain maximum value of frictional force and high degree of cornering force. In braking situation, if the $s>s_{\text {down }}$, the braking actuator at the ABS hydraulic unit activated and the valve is closed. As a consequence, the braking force at the wheel cylinder and calliper become zero. This allows the tire to rotate and prevent it from lock-up. On the other hand, if 
the $s<s_{u p}$, the hydraulic valve opened, and the braking force is applied at the wheel cylinder and calliper. Then, the speed of the tire and the slip ratio increased. From this mechanism, the value of $s$ stays in its optimum range.

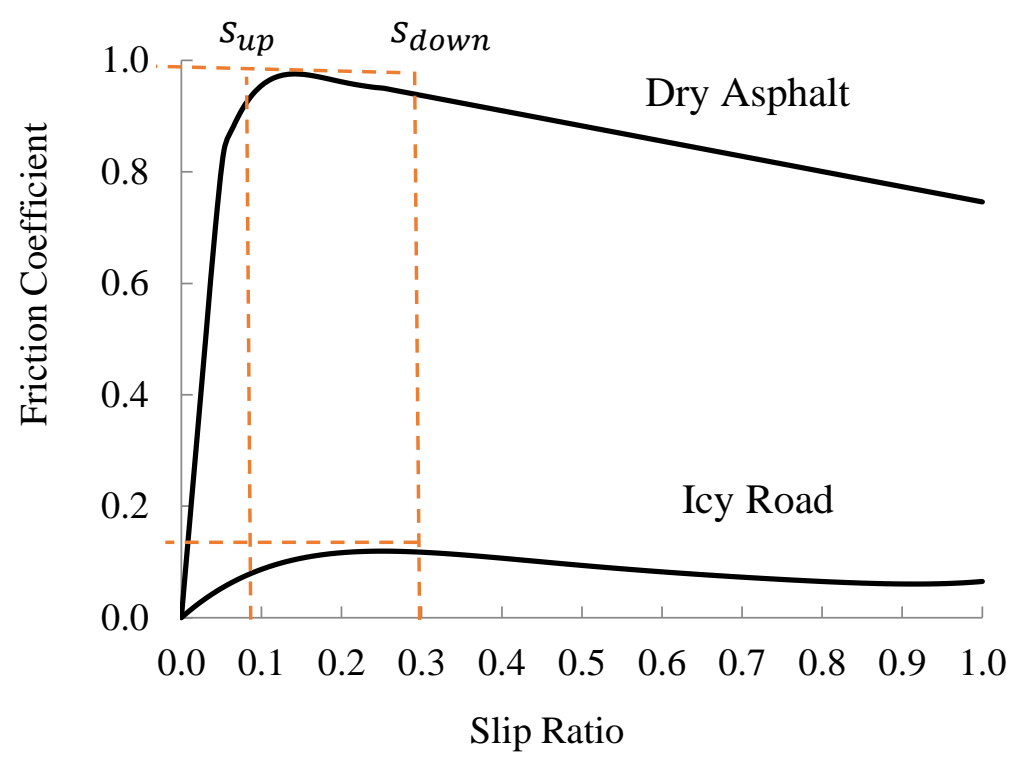

Figure 4 Relation between slip ratio and friction coefficient

\section{RESULTS AND DISCUSSION}

Table 4 shows the simulated result of panic braking under dry condition with the assist of $\mathrm{ABS}$ and without it. From the table, the stopping distance and stopping time simulated with the assist of ABS, is shorter than without assist of ABS.

Table 4. Simulated result of panic braking under dry condition.

\begin{tabular}{lcccccc}
\hline $\begin{array}{l}\text { Speed } \\
(\mathrm{km} / \mathrm{h})\end{array}$ & \multicolumn{2}{c}{ Stopping distance $(\mathrm{m})$} & Improvement & \multicolumn{2}{c}{ Stopping time $(\mathrm{s})$} & Improvement \\
\cline { 2 - 3 } \cline { 5 - 6 } & $\mathrm{ABS}$ & No ABS & & ABS & No ABS & $(\%)$ \\
\hline 30 & 4.64 & 5.62 & 21 & 1.17 & 1.42 & 21 \\
50 & 11.24 & 13.92 & 24 & 1.75 & 2.14 & 23 \\
70 & 16.56 & 34.06 & 106 & 1.78 & 3.55 & 99 \\
\hline
\end{tabular}

Figure 5 shows the stopping distance during panic braking with and without ABS under dry road condition. The line colour in the figure represent initial speed of the vehicle before panic braking which, black line for $30 \mathrm{~km} / \mathrm{h}$, red line for $50 \mathrm{~km} / \mathrm{h}$, and blue line for $70 \mathrm{~km} / \mathrm{h}$. From Figure 5, it can be seen that the higher distance taken for the vehicle to stop is at the higher speed. It also shows that with ABS assist, the stopping distance for the vehicle is shorter than without the assist of ABS for all different initial speed.

The vehicle and tire speed during panic braking with ABS is shown in Figure 6(a), while without ABS is shown in Figure 6(b). As referred from Figure 6(a), the speed of the front tires for all speed are fluctuating, which means that the ABS is activated. However, the speed for the rear tire is decreased smoothly and the same pattern with the speed of the vehicle. Based on the specification of the brake system for analysis vehicle model, a bigger piston is installed at the front wheel since more stopping power is needed. During panic braking, the longitudinal 
acceleration, $a$ is increased rapidly and causes more weight transferred from the rear wheel to the front wheel. To prevent the front tire from lock-up, the ABS is activated at the front tire. On the other hand, the braking force at the rear tire is less than the front tire and the ABS is not activated. Contrarily, without ABS, from Figure 6(b), the front tires experience wheel lock-up, while the rear tires are decreased gradually. It happens due to the high pressure at the calliper and piston that lead to the enormous amount of brake pressure at front wheels causing tire to lock and skid.

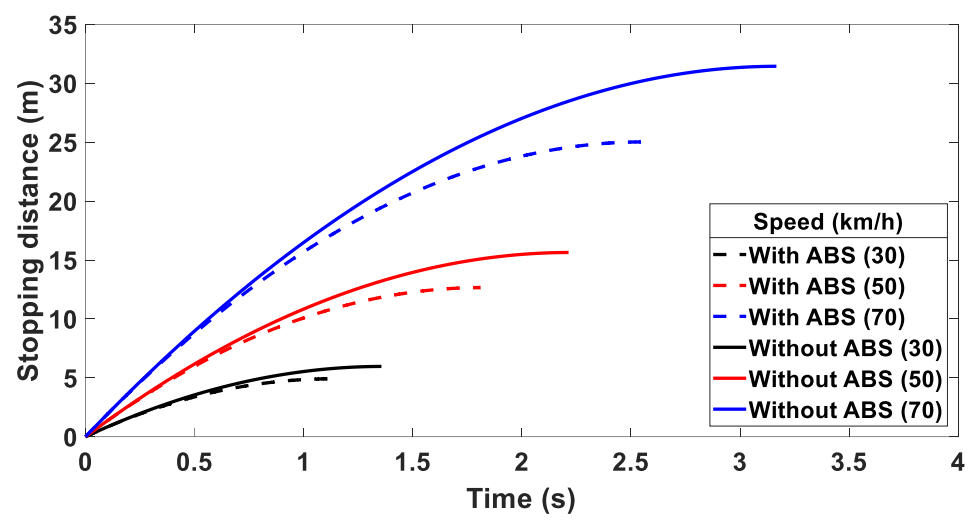

Figure 5. Simulated result of stopping distance during panic braking with and without ABS under dry condition.

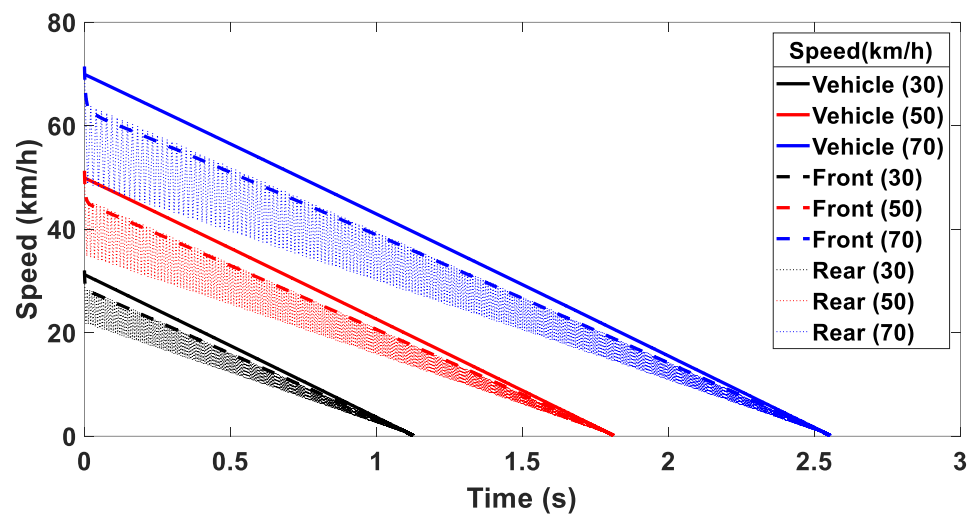

(a)

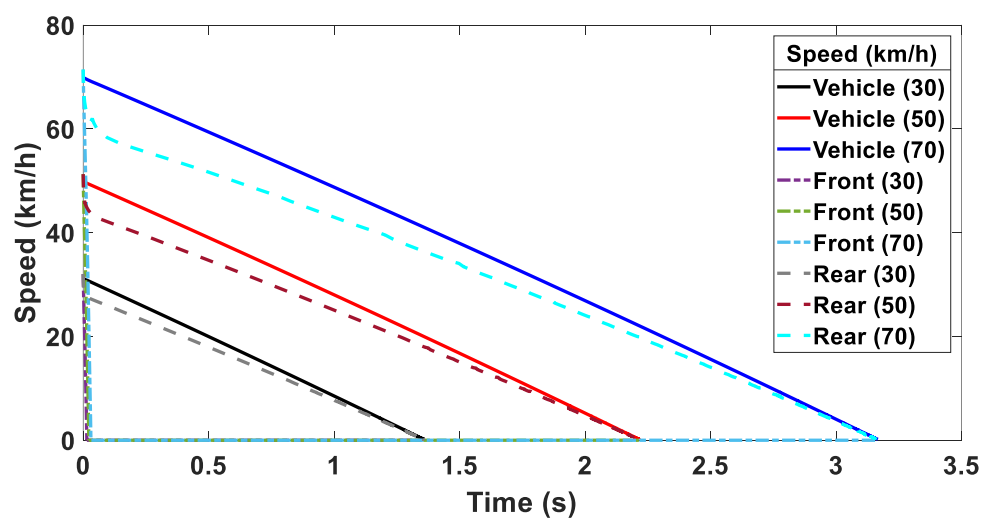

(b)

Figure 6. Simulated result of vehicle and tires during panic braking (a) with and; (b) without ABS under dry condition. 
The effect of ABS also can be illustrated by the slip ratio as shown in Figure 7. For all speed, with ABS activated, the slip ratio of the front tire is kept in between 0.08 to 0.30 . At rear tire, the slip ratio ranging from 0.08 to 0.11 which is within the optimal slip ratio. Hence, no ABS is activated at the rear tire at each different speed. Without ABS, as can be seen from Figure $7(\mathrm{~d})$, the front tire slip ratio rises to 1 in mere seconds. Slip ratio 1 indicates a wheel lock while 0 indicates free rolling. The slip ratio for rear tire maintains around 0.12 to 0.15 which is within the optimal range. Front tire is lock easier due to the weight transfer during braking and huge braking force at the disc brake which increase the grip on the front tires.

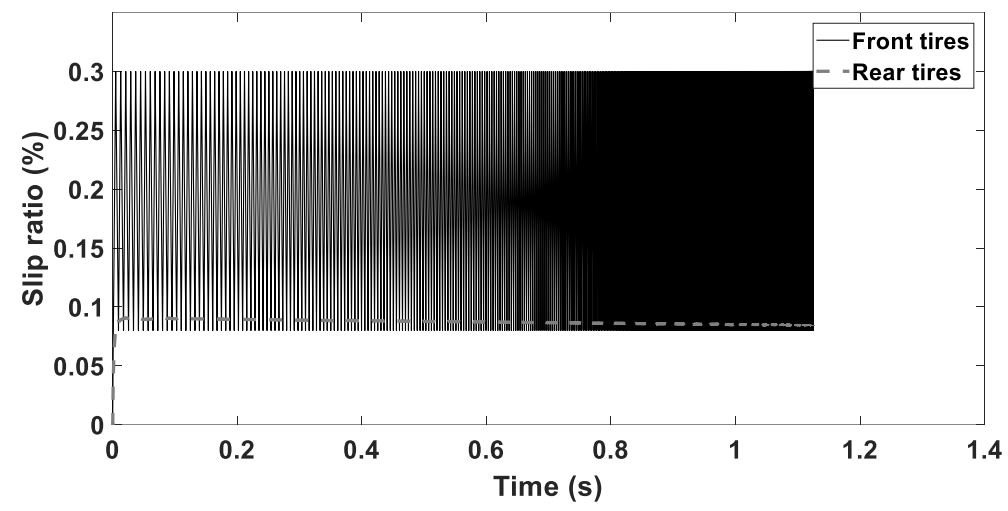

(a)

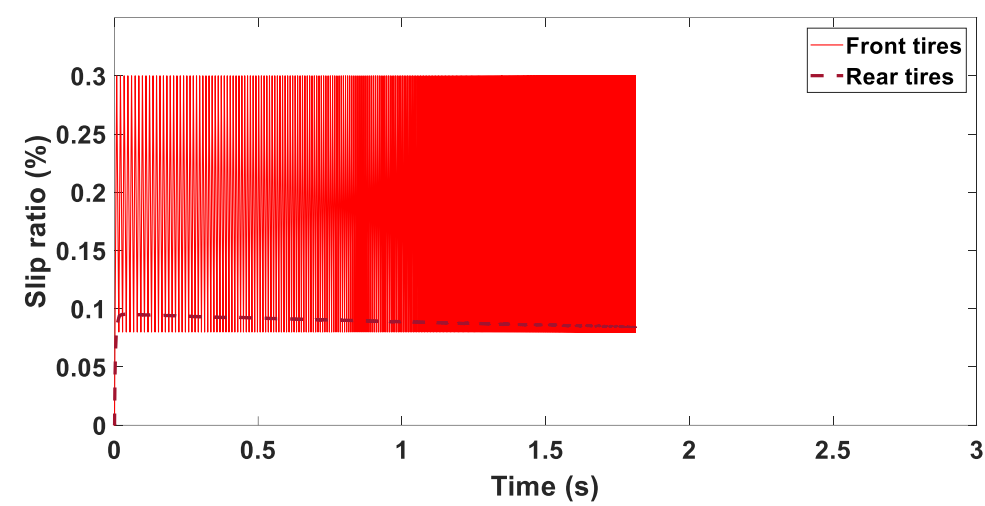

(b)

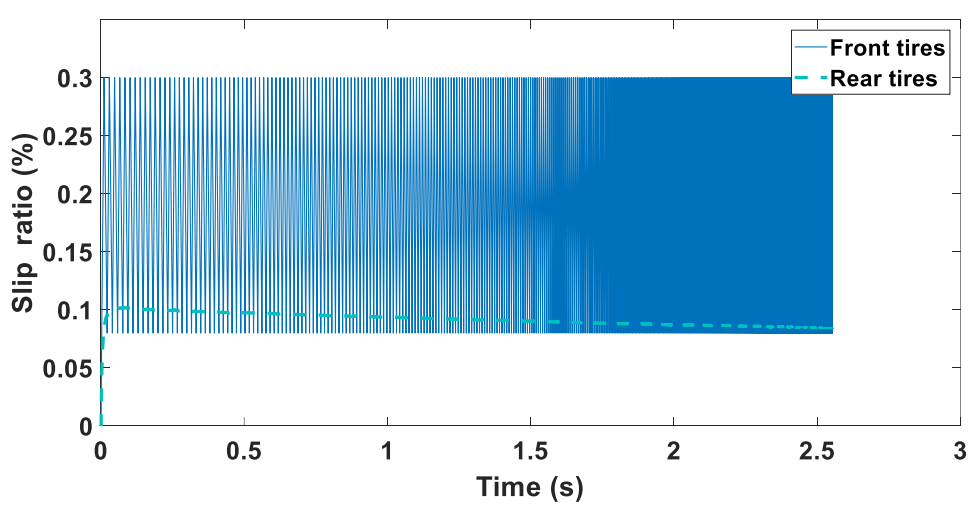

(c) 


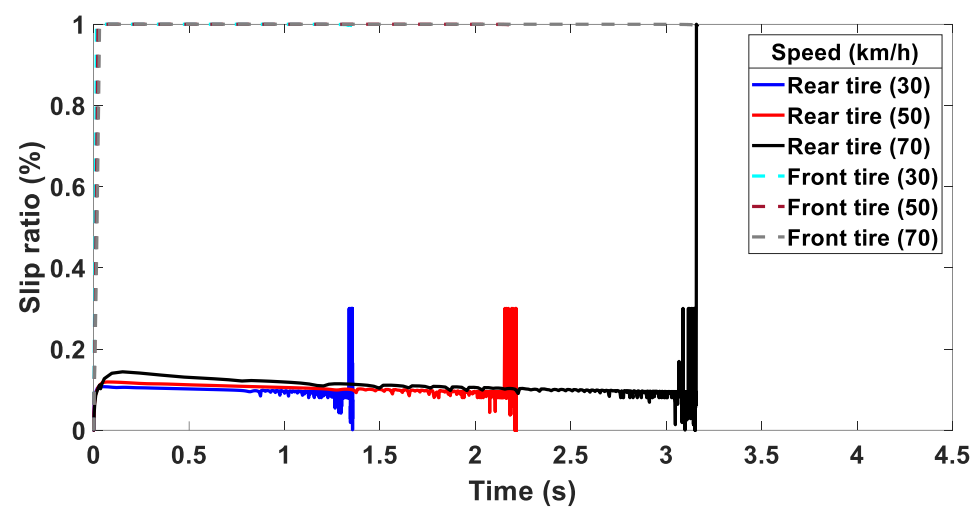

(d)

Figure 7 Simulated result of tire slip ratio during panic braking under dry condition at speed of (a) $30 \mathrm{~km} / \mathrm{h}$ with ABS; (b) $50 \mathrm{~km} / \mathrm{h}$ with ABS; (c) $70 \mathrm{~km} / \mathrm{h}$ with ABS; (d) all speed without ABS.

\section{CONCLUSION}

In this paper, a simulation model of VGPS UMP test car was developed in MATLAB-Simulink. The simulation conducted to understand the dynamics behaviour of the vehicle during panic braking under dry condition. Three different initial speeds were applied to the model, and each speed are simulated with ABS and without ABS activated. The simulation results show that due to the sudden and large amount of braking torque, the tire is locked-up when ABS is not applied to the vehicle. In this situation, the vehicle was skidding and as a result, the stopping time and distance became longer. However, when ABS is applied to the vehicle, the maximum friction force is created between the tire and road surface. Therefore, the tire is not locked up and the vehicle is more stable than without ABS. It can be concluded that ABS can prevent the tire from locking up during panic braking and improve the safety of the vehicle.

\section{ACKNOWLEDGEMENT}

The authors would like to thank Ministry of Higher Education Malaysia for providing Fundamental Research Grant Scheme (FRGS) under project number RDU160138. Special thanks to Automotive Engineering Centre, Universiti Malaysia Pahang (www.ump.edu.my) for providing research grant under project number RDU 160312 and providing a Test Car and technical support for this research.

\section{REFERENCES}

[1] Kassim KAA, Arokiasamy L, Isa MHM, Osman I. Automotive Consumerism towards Car Safety in Malaysia. Procedia - Social and Behavioral Sciences. 2016;219:424-30.

[2] Darma Y, Karim MR, Abdullah S. An analysis of Malaysia road traffic death distribution by road environment. Sadhana-Acad P Eng S. 2017;42:1605-15.

[3] Rolison JJ, Regev S, Moutari S, Feeney A. What are the factors that contribute to road accidents? An assessment of law enforcement views, ordinary drivers' opinions, and road accident records. Accid Anal Prev. 2018;115:11-24.

[4] Asgarzadeh M, Verma S, Mekary RA, Courtney TK, Christiani DC. The role of intersection and street design on severity of bicycle-motor vehicle crashes. Injury Prev. 2017;23:179-85. 
[5] Jeong E, Oh C. Evaluating the effectiveness of active vehicle safety systems. Accident Anal Prev. 2017;100:85-96.

[6] Matthews G, Neubauer C, Saxby DJ, Wohleber RW, Lin J. Dangerous intersections? A review of studies of fatigue and distraction in the automated vehicle. Accident Anal Prev. 2018.

[7] Zhang JH, Sun WC, Feng ZG. Vehicle yaw stability control via H-infinity gain scheduling. Mech Syst Signal Pr. 2018;106:62-75.

[8] Wang FC, Chen Y. Dynamics and Control of a Novel Active Yaw Stabilizer to Enhance Vehicle Lateral Motion Stability. J Dyn Syst-T Asme. 2018;140.

[9] Ji XW, He XK, Lv C, Liu YH, Wu J. A vehicle stability control strategy with adaptive neural network sliding mode theory based on system uncertainty approximation. Vehicle Syst Dyn. 2018;56:923-46.

[10] Berlemann M, Matthes A. Positive externalities from active car safety systems. Journal of Policy Modeling. 2014;36:313-29.

[11] Mortimer R.G., Segel L., Dugoff H. , Campbell J.D., Jorgesen C.M., Murphy RW. Brake force requirement study driver vehicle braking performance as a function of brake system design variables. HSRI Report1970. p. 1-122.

[12] Licea MR, Cervantes I. A Robust Approach to Mitigate the Lateral Skid for Wheeled Vehicles. Ieee Lat Am T. 2018;16:1306-13.

[13] Peeie MHB, Ogino H, Oshinoya Y. Skid control of a small electric vehicle with two inwheel motors: simulation model of ABS and regenerative brake control. International Journal of Crashworthiness. 2016;21:396-406.

[14] Lee HK, Shin SG, Kwon DS. Design of Emergency Braking Algorithm for Pedestrian Protection Based on Multi-Sensor Fusion. Int J Auto Tech-Kor. 2017;18:1067-76.

[15] Fildes B, Keall M, Bos N, Lie A, Page Y, Pastor C, et al. Effectiveness of low speed autonomous emergency braking in real-world rear-end crashes. Accident Anal Prev. 2015;81:24-9.

[16] Koglbauer I, Holzinger J, Eichberger A, Lex C. Autonomous emergency braking systems adapted to snowy road conditions improve drivers' perceived safety and trust. Traffic Inj Prev. 2018;19:332-7.

[17] Thomas E, Bianco A, Raia T, Messina G, Tabacchi G, Bellafiore M, et al. Relationship between velocity and muscular endurance of the upper body. Human Movement Science. 2018;60:175-82.

[18] Charlton SG, Starkey NJ. Driving on urban roads: How we come to expect the 'correct' speed. Accident Anal Prev. 2017;108:251-60.

[19] Montella A, Aria M, D'Ambrosio A, Galante F, Mauriello F, Pernetti M. Simulator evaluation of drivers' speed, deceleration and lateral position at rural intersections in relation to different perceptual cues. Accident Anal Prev. 2011;43:2072-84. 